\title{
"LOUCURA DO POVO E LOUCURA DA BURGUESIA". BAUDELAIRE: ATOR, POETA E JUIZ DA REVOLUÇÃO DE 1848*
}

\author{
Dolf OEHLER \\ Universidade de Bonn \\ "Assez de lyre !" \\ (Un ouvrier à Lamartine, 1848) \\ "Combien prête-t-on sur une lyre \\ au Mont-de-Piété ?" \\ (Charles Baudelaire, 1852) ${ }^{1}$
}

ara os nossos propósitos, podemos classificar o corpus de textos baudelairianos concernentes ao nosso tema em três categorias: $1^{\circ}$ Os textos redigidos por assim dizer "no calor da hora", durante a Segunda República, inclusive os artigos jornalísticos; $2^{\circ}$ os textos escritos após o golpe de Estado e que retomam a experiência da Revolução; $3^{\circ}$ as anedotas que tratam do Baudelaire revolucionário. Comecemos pelas últimas.

A imagem de Baudelaire em 1848 permanece, ainda hoje, fortemente influenciada, quando não determinada, pelas anedotas. A maior parte das anedotas baudelairianas foi recolhida por T. W. Bandy e Cl. Pichois em sua imortal antologia de

\footnotetext{
* Tradução de Daniel dos Santos Garroux.

1 "Basta de lira!"

(Um trabalhador a Lamartine, 1848).

"Quanto se consegue por uma lira

no Mont-de-Piété?"

(Charles Baudelaire, 1852)
} 
1957, intitulada Baudelaire devant ses contemporains e reeditada em forma de livro de bolso pela editora 10/18. Quanto à questão do engajamento revolucionário do jovem Baudelaire, a anedota emblemática continua sendo sem dúvida aquela contada por Jules Buisson em uma carta a Eugène Crepet. Até onde sei, este último cita a anedota pela primeira vez em 1886 e, depois disso, em seu estudo biográfico de 1906, portanto cerca de 40, ou mesmo, no segundo caso, 58 anos após os fatos. A anedota mostra Baudelaire na noite de 24 de fevereiro de 1848 no carrefour Buci, brandindo "um belo fuzil de dois tiros reluzente e intacto" e gritando sem cessar "seu refrão": "precisamos fuzilar o general Aupick !". ${ }^{2}$ Ao longo de todo o século XX o refrão serviria de palavra de ordem para aquilo que Walter Benjamin denominaria a recepção conformista de Baudelaire. Eu diria que ele serviu de chave de leitura não apenas para biografia de Baudelaire, mas igualmente para sua obra e para a história da boêmia de 1848 como um todo. Ao dizer "recepção conformista", não me refiro apenas à recepção do público conservador, penso também na leitura que a maior parte dos intelectuais de esquerda, a começar por Aragon e Sartre, fez da obra de Baudelaire. Sartre não conferiu tanta importância a esta anedota quanto o editor das obras de Baudelaire na Bibliothèque de la Pléiade, ninguém menos que Claude Pichois, o mesmo que, em sua biografia do poeta, intitulou o capítulo sobre a Revolução: "É preciso fuzilar o general Aupick!", 3 O fato de Baudelaire, que nutria tão grande desprezo por anedotas, assim como pelos franceses apreciadores de anedotas, ter sido vítima da mania anedótica de seus compatriotas é uma dessas ironias de que a história da poesia moderna está repleta.

Entretanto, já que se trata de anedotas, existe outra anedota sobre 48, esta bem mais perturbadora, e que Bandy e Pichois como que por acaso se esqueceram de acrescentar à sua coletânea. Vou trazê-la à baila porque fala de um acontecimento e de um engajamento bem mais arriscado. Uma anedota que foi revelada por outro amigo de Baudelaire, Gustave Le Vavasseur, e que começa por uma constatação tão lapidar quanto chocante: "Baudelaire participou, como insurgente, nas jornadas de junho". E o testemunho prossegue: "Estávamos no Louvre, em guarda [...] durante as jornadas de junho. Logo após a rendição do Faubourg Saint-Antoine, ou seja, em 26 de junho, saímos para reconhecer o terreno e obter informações. Encontramos, no jardim do Palais-Royal, um integrante da guarda nacional de nosso país, e o levamos para beber algo. Na diagonal mesma em que seguíamos para chegar ao café de Foy avistamos, vindo em nossa direção, dois personagens de aparências diversas: um estava nervoso, excitado, febril e agitado, o outro calmo, quase distraído. Eram Baudelaire e Pierre Dupont. Entramos no café. Eu nunca vira Baudelaire em tal estado. Ele discursava, declamava, exaltavase e preparava-se para enfrentar o martírio: 'Acabaram de prender De Flotte, dizia. Terá sido porque suas mãos cheiravam a pólvora? Mas sinta o cheiro das minhas!'. Em seguida os arroubos socialistas, a apoteose da bancarrota social etc. Não havia nada que Dupont pudesse fazer. De que modo nossas prudências normandas tiraram

\footnotetext{
${ }^{2}$ Citado segundo Baudelaire devant ses contemporains, 10/18, Paris, Union Générale d'Édition,

${ }^{3}$ C. Pichois; J. Ziegler, Charles Baudelaire, Paris, Fayard, 1996, cap. XIV, p. 255-292.
} 1967, p. 97. 
nosso amigo daquela enrascada? Já não me lembro mais. Penso, porém, que a insígnia de meu amigo da guarda nacional exerceu um papel importante, claro e salutar na pequena comédia da salvação". E o narrador acrescenta: "A despeito do que se possa pensar da coragem de Baudelaire, naquele dia ele foi um bravo, $\mathrm{e}$ enfrentaria a morte". ${ }^{4}$ Ao contrário daquela de fevereiro de 1848, a anedota das Jornadas de Junho foi pouco reproduzida e ainda menos comentada. Alguém que ignorasse o papel exercido pela insurreição de junho de 48 não seria capaz de perceber o seu alcance. Ora, para compreendê-la melhor, seria interessante evocar a lembrança do magnífico artigo que Marx escreveu logo após as jornadas de junho na Nouvelle Gazette Rhénane, intitulado Die Junirevolution. Esse artigo opõe fevereiro a junho de 48: "A revolução de fevereiro foi a bela revolução [...]. A revolução de junho é a revolução hedionda, a revolução repugnante, porque as frases deram lugar à realidade [...]. "Hedionda" porque junho foi a revolução apenas dos proletários, que a burguesia e seus jovens abandonaram à própria sorte. Marx insiste na abstinência revolucionária da juventude republicana ou socialista durante essas jornadas. E de fato, entre as fileiras de insurgentes de junho quase não se pode encontrar estudantes, politécnicos ou até mesmo artistas e poetas. Não se deve subestimar o fato de Baudelaire ser o único entre os grandes nomes das letras e das artes a apoiar os insurgentes de junho. Não é simples acaso, tampouco, que ele estivesse acompanhado por Pierre Dupont, seu amigo lionês, e nem que, tal como narra a anedota, não tenha sido o autor do Chant des Ouvriers [Canto dos trabalhadores] quem arrastou o dandy ao combate, mas provavelmente o contrário. Enfim, há ainda outra coisa que o relato de Le Vavasseur coloca em evidência: é o fato de que, imediatamente após a derrota de junho, o insurgente Baudelaire que rivaliza com o blanquista De Flotte - um dos grandes nomes da extrema esquerda que os parisienses conduzirão à assembleia nacional legislativa durante as eleições de março de $1850^{6}$ - o poeta insurgente, portanto, proclama uma teoria revolucionária, e isso num café mundano, cujo público está se recuperando do susto que levou, e onde, normalmente, não há ninguém para lamentar a derrota dos trabalhadores e prognosticar a bancarrota social. Num momento como esse, vociferar contra a república burguesa em pleno café de Foy e insistir no fato de ter levantado fogo ao lado dos insurgentes significava expor-se não apenas à prisão, mas à deportação ou coisa pior.

Essa narrativa, se tomada a sério, pode mostrar que a seção "Revolta" das Flores do mal é bem mais do que o alegado pela famigerada nota da primeira edição de 1857, a saber, "o pastiche dos raciocínios da ignorância e da fúria" (OC, I, 1075 sq.). Nota técnica que ele qualificará de "detestável" em uma carta a seu editor Poulet-Malassis (ele mesmo um antigo insurgente de junho), e que será suprimida na segunda edição. O comportamento suicida do poeta do café de Foy remete sobretudo à última estrofe d'A negação de São Pedro [Le reniement de Saint-Pierre],

${ }^{4}$ E. Crépet, Charles Baudelaire, Paris, Messein, 1906, p. 80.

${ }^{5}$ Marx cita seu próprio artigo no primeiro capítulo de Luttes de classes en France [As lutas de classe na França], Paris, Gallimard, 1984, p. 39.

${ }^{6}$ Ver Marx, Luttes de classes en France, op. cit., p. 124. 
na qual Benjamin revelou a grande afinidade do poeta d'As flores do mal com a política de Blanqui:

Certes, je sortirai, quant à moi, satisfait.

D’un monde où l'action n'est pas la soeur du rêve.

Puissé-je user du glaive et périr par le glaive.

Saint Pierre a renié Jésus... il a bien fait ! (OC, I, 122)

A fórmula de Benjamin segundo a qual "a ação de Blanqui foi a irmã do sonho de Baudelaire" 8 tornou-se célebre e chocou mais de um, não somente Adorno e Brecht. Este último que, como se sabe, afirmou tão duramente o seu caráter inadmissível pela contra-fórmula: "Baudelaire era uma punhalada nas costas de Blanqui". ${ }^{9}$ Contudo, o próprio Benjamin parece ignorar o testemunho de Le Vavasseur, uma vez que parte de uma correlação um tanto rígida entre a ação de um e a utopia de outro, quando na verdade Baudelaire, ao tomar o partido dos insurgentes de junho e ao engajar-se nas grandes ocasiões revolucionárias, fez o que sonhou e pregou como poeta. Longe de delegar a ação aos revolucionários profissionais, o próprio Baudelaire pegou em armas: tanto em junho como em fevereiro, e também mais tarde, por ocasião do golpe de Estado de Louis Bonaparte. Ao contrário de seu amigo Flaubert, Baudelaire não assistiu como testemunha a todos os conflitos de seu tempo, mas participou deles ativamente, e sempre do lado dos insurgentes.

Pelo viés do testemunho anedótico introduzimo-nos na discussão da seção das Flores do mal cujos poemas estão mais ostensivamente ligados à história de 48. Para começar, relembraria as célebres palavras de Paul Valéry: "O problema de Baudelaire poderia, portanto [...] ser colocado da seguinte maneira: 'ser um grande poeta, mas não ser nem Lamartine, nem Hugo, nem Musset". ${ }^{10}$ E Benjamin observa, acrescentando, que Baudelaire "escrevia alguns de seus poemas com o propósito de destruir alguns outros, redigidos antes dele. No que diz respeito aos seus poemas políticos, digamos que Baudelaire se empenha em aprimorar e a ultrapassar, quando não a destruir alguns poemas de Auguste Barbier, de Victor Hugo, certamente, e, sobretudo, de Pierre Dupont. Este último, seu companheiro de insurreição, é visto pelo próprio Baudelaire como o poeta de 1848, e seu Chant des Ouvriers, apesar de escrito em 1846, é celebrado no prefácio de Chants et Chansons [Cantos e canções] como "a Marselhesa do trabalho" (OC, II, 31), o hino revolucionário por excelência:

\footnotetext{
7 "Quanto a mim, isto é certo, eu saio satisfeito/ Desse mundo onde o sonho e a ação vivem a sós;/ Possa eu usar a espada e a espada ser meu algoz !/ São Pedro renegou Jesus... Pois foi bem-feito !". Charles Baudelaire, As flores do mal, trad. Ivan Junqueira, Rio de Janeiro, Nova Fronteira, 1985, p. 419. [N.T.]

${ }^{8}$ Cf. Walter Benjamin, Charles Baudelaire, trad. J. Lacoste, Paris, Payot, [1982], p. 144 sq. Vale notar que essa aproximação entre Blanqui e Baudelaire se situa em uma posição estratégica nos textos que Walter Benjamin consagrou ao poeta das Flores do mal: ele fecha o terceiro e último ensaio do livro "A Paris do Segundo Império em Baudelaire", intitulada La Modernité. Em contrapartida, a figura de Blanqui será banida em Sobre alguns temas em Baudelaire, o único texto sobre Baudelaire que Benjamin publicou em vida, sob o crivo dos editores da Zeitschrift für Sozialforschung.

${ }^{9}$ Cf. Bertolt Brecht, Über Lyrik [Sobre a Lírica], Frankfurt/M., Suhrkamp, 1964, p. 69.

${ }^{10}$ Paul Valéry, "Situation de Baudelaire", in OEuvres complètes I, Bibliothèque de la Pléiade, p. 600
} 
"Cabe a Pierre Dupont a eterna honra de ter pela primeira vez arrombado a porta. De machado em punho, ele cortou as correntes da ponte levadiça da fortaleza" (OC,II, 34). Segundo o prefácio de Baudelaire, a poesia de Dupont anuncia a morte da melancolia romântica ao fazer uma denúncia rigorosa da iniquidade social. Dez anos mais tarde, numa época em que toda a crítica estava pronta a atacar asperamente as canções políticas de Dupont, Baudelaire vai se tornar um reincidente, sobretudo pelo elogio enfático que faz do Chant des Ouvriers, do qual ele cita a mesma estrofe que Karl Marx irá reproduzir numa nota do Capital: ${ }^{11}$

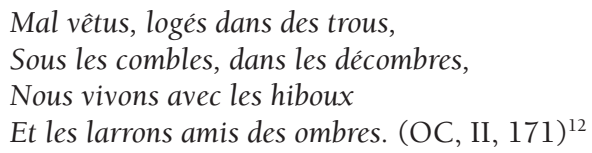

para então concluir numa prosa de admirável precisão poética: "Esse canto era um desses átomos voláteis que flutuam pelo ar e cuja aglomeração se torna trovoada, tempestade, um grande acontecimento? [...] Não sei; o fato é que pouco tempo, muito pouco tempo depois, esse hino retumbante iria se adaptar admiravelmente a uma revolução geral na política e nas aplicações da política. Ele se tornava, quase imediatamente, o grito de guerra das classes desfavorecidas" (ibidem, 173 sq.). Levando em consideração a intensidade e a lucidez dos dois comentários que Baudelaire dedicou a Dupont, podemos nos perguntar se não teria havido, ao menos antes do dois de dezembro de 1851, um período de rivalidade com o chansonnier que, em duas ocasiões, ele associa a um de seus ídolos: Proudhon? E se ele também não teria nutrido a intenção de produzir textos que se tornassem gritos de guerra das classes desfavorecidas? Le reniement de Saint-Pierre - poema que de fato renega o Cristo da "bela" Revolução de Fevereiro, por ele não ter persistido em sua empresa anticapitalista - depõe a favor da hipótese de uma rivalidade de Baudelaire com Dupont.

O poema o representa como um crucificado que recorda com pesar, no momento de sua agonia,

[...] ces jours si brillants et si beaux [...]

Où, le coeur tout gonflé d'espoir et de vaillance,

Tu fouettais tous ces vils marchands à tour de bras,

Où tu fus maître enfin ? (OC, I, 121 sq. $)^{13}$

Com efeito, o poeta desaprova em Cristo sua prontidão para renunciar à violência salutar e para adotar uma atitude de vítima que obedece aos desígnios de um deus sádico, ou até mesmo diabólico. É evidente para todo leitor minimamente

${ }^{11}$ Ele o faz no contexto de uma análise de um hábitat. Cf. Karl Marx, Das Kapital. Kritik der politischen Ökonomie, Köln, Parkland Verlag, 2000, p. 642.

12 "Mal vestidos, vivendo em buracos,/ Nos sótãos, nos escombros,/Vivemos com as corujas/ e com os larápios amigos das sombras". [N.T.]

13 "[...] esses dias cheios de esplendores [...]/ Em que, a alma pródiga de audácia e de esperança,/ Aos vendilhões do templo açoitavas o dorso,/ Em que tu foste o mestre enfim?". Charles Baudelaire, As flores do mal, op. cit., p. 417-419. [N.T.] 
atento que, na última estrofe do Reniement, Baudelaire se contrapõe à poesia revolucionária de seu amigo Dupont, o qual tangia os bordões de 48 com refrões como os do Chant des Nations [Canto das nações]:

Le glaive brisera le glaive,

Et du combat naîtra l'amour ${ }^{14}$

ou ainda aos versos do Chant des Transportés [Canto dos exaltados]:

Quand Jésus a dit à saint Pierre:

L'épée au fourreau doit dormir,

Pourquoi voyons-nous son vicaire

Et ses cardinaux la rougir ? ${ }^{15}$

Este é o refrão do Chant des Nations que Baudelaire retoma com mais frequência. Sem dúvida porque ele o considera um concentrado das ilusões de Fevereiro: "Pierre Dupont é uma alma delicada com inclinação para utopias e, por isso mesmo, verdadeiramente bucólica", observa ele no segundo comentário, com um sarcasmo mal dissimulado. "Tudo nele se transforma em amor, e a guerra, tal como ele a concebe, não é senão uma maneira de preparar a reconciliação universal":

Le glaive brisera le glaive,

Et du combat naîtra l'amour (OC, II, 172)

Nessa passagem, Baudelaire insere sua própria filosofia da história numa simples asserção: "Há em seu espírito certa força que resulta sempre em bondade; e sua natureza, pouco propensa a resignar-se às leis eternas da destruição, não quer aceitar idéias consoladoras" [itálicos nossos]. Baudelaire retoma, portanto, a crítica que já havia feito a esses versos em seu prefácio de 1851: "Dupont constatou, talvez de modo inconsciente, a utilidade do espírito de destruição. Ele deixou escapar essa confissão, mas vejam em que termos:

Le glaive brisera le glaive,

Et du combat naîtra l'amour" (OC, II, 33)

Essa visão kitsch é então refutada pelo "Puissé-je user du glaive et périr par le glaive !"16 do primeiro poema de Révolte [Revolta]. Do mesmo modo, Abel et Caïn [Abel e Caim] investe contra o culto da fraternidade, aquela fraternidade que constitui, segundo Marx "a verdadeira divisa da revolução de Fevereiro"; ${ }^{17}$ fraternidade que todos os poetas de 48 , salvo raras exceções, pregavam:

\footnotetext{
${ }^{14}$ Pierre Dupont, Chants et poésies, Paris, Garnier Frères, 1875, p. 75 sq. "A espada romperá a espada/ E do combate nascerá o amor".

${ }^{15}$ Idem, ibidem, p. 38. ["Quando Jesus disse a São Pedro:/ A espada na bainha deve dormir,/Por que nós vemos seu vigário/E seus cardeais cobrirem-na de vermelho?".]

16 "Possa eu usar a espada e a espada ser-me o algoz!" [N.T.]

${ }^{17}$ Cf. Marx, op. cit., p. 24.
} 
32 Literatura e Sociedade

Peuples, venez de toutes parts

Voir la République nouvelle,

Douce comme une tourterelle,

Formidable comme un rempart :

Frères, serrons-nous autour d'elle. ${ }^{18}$

Os acontecimentos tornaram rapidamente anacrônico o refrão de outra canção de Dupont, La Jeune République (1848), e quase tão ingênuo quanto os versos seguintes:

Que l'argent circule à plein bord

Comme un fleuve qui vivifie,

Que dans un fraternel accord

Le riche au pauvre se confie ! ${ }^{19}$

Um poema como Abel et Cain corrige esses anseios piedosos oriundos da embriaguez de Fevereiro por acentos de luta de classe em que se alternam mordacidade satírica e pathos militante:

Race d'Abel, chauffe ton ventre

A ton foyer patriarcal ;

Race de Cain, dans ton antre

Tremble de froid, pauvre chacal!

Race d'Abel, aime et pullule!

Ton or aussi fait des petits.

Race de Caïn, coeur qui brûle,

Prend garde à ces grands appétits.

Race d'Abel, tu crois et broutes

Comme les punaises des bois!

Race de Caïn, sur les routes

Traîne ta famille aux abois. (OC, I, 122 sq.) ${ }^{20}$

E o imperativo final do poema, sua tirada blasfematória, é uma variação tonitruante da sentença de Marx segundo a qual a religião é o ópio do povo:

Race de Caïn, au ciel monte

Et sur la terre jette Dieu !21

${ }^{18}$ Pierre Dupont, Chants et poésies, op. cit., p. 143 ss. ["Homens, venham de toda parte/ Para ver a nova República,/ Doce como uma pomba,/ Formidável como uma muralha :/ Irmãos, vamos dar as mãos em volta dela."]

${ }^{19}$ Pierre Dupont, Chants et poésies, op. cit., p. 144. ["Que a prata circule em abundância/ Como um rio que vivifica, / Que num acordo fraternal /O rico no pobre se fie!"]

20 "Raça de Abel, teu ventre aquece/ Junto à lareira patriarcal;// Raça de Caim, treme e padece/ Em teu covil, pobre chacal!// Raça de Abel, goza e pulula!/ Teu ouro é pródigo em rebentos;// Raça de Caim, refreia a gula,/ Ó coração que arde em tormentos!// Raça de Abel, cresces e brotas/ Como os insetos do arvoredo;// Raça de Caim, por ínvias rotas,/ Arrasta os teus à infâmia e ao medo." Charles Baudelaire, As flores do mal, op. cit., (p. 421). [N.T.]

21 "Raça de Caim, sobe ao espaço/ E Deus enfim deita por terra!" Charles Baudelaire, As flores do mal, op. cit., (p. 421). [N.T.] 
Eis aí um grito de guerra das classes desfavorecidas bem mais subversivo que o relativamente ameno Chants des Ouvriers! Entretanto, o grito baudelairiano encontrou pouca ressonância, ao menos entre aqueles aos quais ele talvez se destinasse. O famoso "É preciso fuzilar o general Aupick!" está longe de ser a única frase de Baudelaire que seus exegetas bem-pensantes utilizaram, e continuam utilizando, como para-raios ideológico. Quando se trata da maturidade do poeta e de sua evolução após o golpe de Estado de 2 de dezembro de 1851, recorrem de preferência a algumas pequenas frases retiradas dos Journaux intimes como "De Maistre e Edgar Poe me ensinaram a raciocinar" (OC, I, 669) ou ainda:

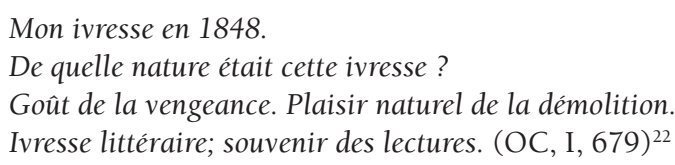

Essas citações nos são impostas sem que se leve em conta seu status de anotações privadas, improvisadas e elípticas. Essa falta de cuidado hermenêutico seria uma tentativa de aproveitar a fundo seu potencial reacionário. É de modo semelhante que se invoca a boutade melancólica contida numa carta a Ancelle: "O 2 de dezembro fisicamente me despolitizou"(Corr., I, 188) para fazer o mesmo com a própria obra poética de Baudelaire e negar seu alcance político. ${ }^{23}$ Insisto na necessidade de fazer uso dos fragmentos inscritos em Mon coeur mis à nu [Meu coração desnudado] com extrema prudência. Quando Pichois e Ziegler, em sua biografia de Baudelaire, corrigem os esquecimentos anteriores que mencionamos acima e reproduzem a anedota de La Vavasseur sobre o engajamento militante do poeta durante as jornadas de Junho, eles imediatamente inventam, para a utilização conformista dos textos baudelairianos, um estratagema tão engenhoso quanto sintomático. Eis no que consiste o estratagema: eles atribuem ao próprio Baudelaire o comentário desse episódio tão insólito, citando simplesmente a anotação dos Journaux intimes: Comentário tardio, irrefutável, de Baudelaire: "Os horrores de Junho. Loucura do povo e loucura da burguesia. Amor natural pelo crime". ${ }^{24}$ É simples assim: o Baudelaire juiz de 1848 condena a si próprio como condena a todos: vencedores e vencidos participando da mesma loucura, da mesma embriaguez! Terrível simplificação, que encontramos nas leituras escolares e mesmo universitárias de outros escritores da revolução de 1848, como Flaubert e Henri Heine, aos quais se atribuem os mesmos sentimentos de um ceticismo equilibrista. Tampouco é colocada a questão sobre se, no espírito de Baudelaire, a loucura do povo teria o mesmo valor do que a da burguesia, postulando-se a igualdade rigorosa de loucuras como um axioma absoluto. O tertium comparationis será, portanto: "O amor natural pelo

\footnotetext{
22 "Minha embriaguez em 1848./ De que natureza era essa embriaguez?/ Gosto pela vingança. Prazer natural com a demolição./ Embriaguez literária; recordação de leituras." [N.T.]

${ }^{23}$ O livro de Pierre Laforgue intitulado Baudelaire dépolitiqué (Paris, Eurédit, 2002) investe fortemente contra tais abusos.

${ }^{24}$ C. Pichois, J. Ziegler, Charles Baudelaire, op. cit., p. 270.
} 
crime". ${ }^{25}$ Esquece-se facilmente que mesmo Flaubert, que nunca militou pela revolução, estabelece uma distinção muito clara entre os erros dos democratas e os dos burgueses em L'education sentimentale - sobretudo no momento de representar as jornadas em seu romance. ${ }^{26}$ Além disso, ele mesmo o dirá diversas vezes em sua Correspondance: "Os Reacionários, de resto, serão ainda menos poupados do que os outros, pois eles me parecem mais criminosos". ${ }^{27}$

Em vez de decifrar os textos poéticos de Baudelaire com base nos Journaux intimes, seria preciso preencher os espaços em branco das anotações íntimas por uma leitura dos poemas. Não são as notas de Mon coeur mis à nu sobre a embriaguez e o ridículo das utopias de 48 que permitem compreender o sentido dos poemas respectivos das Flores do mal ou do Spleen de Paris, e sim o contrário. Graças, por um lado, a poemas como "Le vin de l'assassin" e "Le vin des chiffonniers", por outro, a "A une passante" e Le cygne e, finalmente, a alguns poemas em prosa, como "Enivrez-vous" ou "Assommons les pauvres !", podemos aprofundar e nuançar nossa compreensão do papel político-poético da embriaguez e da loucura em Baudelaire. Por vezes ele glorifica a embriaguez do revoltado, inclusive aquela do lumpemproletariado, como em "Le vin des chiffonniers":

Oui, ces gens harcelés de chagrins de ménage,

Moulus par le travail et tourmentés par l'âge,

Éreintés et pliant sous un tas de débris,

Vomissement confus de l'énorme Paris,

Reviennent, parfumés d'une odeur de futailles,

Suivis de compagnons, blanchis dans les batailles [...] (OC, I, 106 $)^{28}$

E de modo violento toma o partido dos fora da lei, ao mesmo tempo vítimas e críticos da sociedade burguesa:

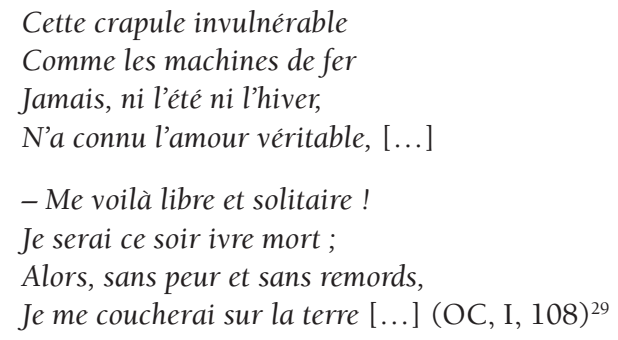

${ }^{25}$ Cf. meu livro, Le Spleen contre l'oubli. Juin 1848, trad. G. Petitdemange e S. Cornille, Paris, Payot, 1996 e as passagens dedicadas ao vocabulário de 1848, especialmente p. 54 a 64.

${ }^{26}$ Cf. o capítulo dedicado a L'education em Le Spleen contre l'oubli, op. cit.

${ }^{27}$ Gustav Flaubert, Correspondance, III, Ed. J. Bruneau, Paris, Gallimard, 1991.

28 "Toda essa gente afeita às aflições caseiras,/ Derreada pela idade e farta de canseiras,/ Trôpega e curva ao peso atroz do asco infinito,/ Vômito escuro de Paris enorme e aflito,// Retorna, a trescalar do vinho as escorralhas, / Junto aos comparsas fatigados das batalhas [...]". Charles Baudelaire, As flores do mal, op. cit., (p. 379). [N.T.]

29 "Essa devassa indiferente,/ Como qualquer engenho hodierno,/ Jamais, no verão ou no inverno,/ Sentiu do amor o apelo ardente, [...]// - Eis-me liberto e a sós contigo!/ Serei à noite um ébrio 
É o que ocorre em "Le vin de l'assassin", publicado pouco depois dos massacres de junho. Bem mais tarde, tendo abandonado a linguagem de 48, até mesmo em sua forma satânica, Baudelaire retornará com frequência à embriaguez revolucionária. E ele fará isso na forma de uma autoanalise coletiva, como em "A une passante", poema que li - aprofundando a intuição benjaminiana - como uma comemoração alegórica do encontro perdido de uma geração com a História, ou, caso prefiram, com o Fantasma da Liberdade:

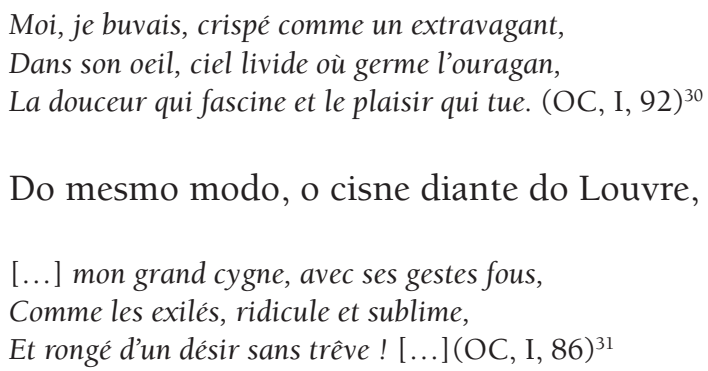

Do mesmo modo, o cisne diante do Louvre,

[...] mon grand cygne, avec ses gestes fous,

Comme les exilés, ridicule et sublime,

Et rongé d'un désir sans trêve ! [...] (OC, I, 86) 31

será outro avatar, supremo avatar da figura do insurgente, símbolo que irá sugerir e fazer reviver a emoção das glórias revolucionárias. Podemos enfim terminar com o mais escandaloso dos poemas em prosa - "Assommons les pauvres !" Não há comentário melhor dos escorços do fólio $\mathrm{V}$ de Mon coeur mis à $n u$, pois esse texto retoma o tema da embriaguez de 1848 e retorna ao motivo da "lembrança de leituras" para esboçar e colocar em cena um contradiscurso paradoxal capaz de refutar tudo o que, àquela época, era lido como elucubrações.

De modo incontestável, Baudelaire zomba aqui das teorias em voga em 1848, inclusive das de Proudhon (que ele outrora havia tanto admirado, a ponto de alertá-lo, pouco depois de junho de 48, contra os desejos homicidas das "bestas ferozes da propriedade" 32 ), sem contudo negar a Revolução enquanto tal, longe disso. ${ }^{33}$ Ele simplesmente aperfeiçoou sua arte de conspirar com a linguagem. ${ }^{34}$

morto; Sem nenhum medo ou desconforto, / Farei da terra o meu abrigo [...]" Charles Baudelaire, As flores do mal, op. cit. (p. 383-385). [N.T.]

30 "Qual bizarro basbaque afoito eu lhe bebia/ No olhar, céu lívido onde aflora a ventania,/ A doçura que envolve e o prazer que assassina." Charles Baudelaire, As flores do mal, op. cit. (p. 345). [N. T.] Cf. Meu ensaio "Autres métamorphoses de la République. Le paradigme baudelairien", in 1848, une revolution du discours, éd. H. Millot/C. Saminadayar-Perrin, Cahiers intempestifs, 2002, p. 43-106.

31 "[...] meu grande cisne, quando em fúria o vi,/Qual exilado, tão ridículo e sublime,/ Roído de um desejo infindo! [...]". Charles Baudelaire, As flores do mal, op. cit. (p. 329). [N.T.]

${ }^{32}$ Carta a P.-J. Proudhon de 21 ou 22 de agosto de 1848, Correspondance, I, p. 152. Lembrete aos não iniciados: Assommons les pauvres! deveria encerrar-se com uma apóstrofe a Proudhon que acabou sendo suprimida

${ }^{33}$ Para mais detalhes, ver Le Spleen contre l'oubli, op. cit., Cap. VI, «Folie dans le style», des Lumières, p. 309-334.

${ }^{34}$ Cf. W. Benjamin, Charles Baudelaire, op. cit., p. 140: "O incógnito era a lei de sua poesia. [...] Baudelaire conspira com a própria linguagem". Será preciso ainda acrescentar que nessa conspiração poética a alegoria bem como a ironia exerce um papel de destaque? 